\title{
The exploration and practice of the integrative and continuous optoelectronic practical teaching system
}

\section{Ying Wang, Xinliang Zhang, Xiaofei Yang, Xiulin Kuang}

Ying Wang, Xinliang Zhang, Xiaofei Yang, Xiulin Kuang, "The exploration and practice of the integrative and continuous optoelectronic practical teaching system," Proc. SPIE 10452, 14th Conference on Education and Training in Optics and Photonics: ETOP 2017, 104521G (16 August 2017); doi: 10.1117/12.2269370

Event: 14th Conference on Education and Training in Optics and Photonics, ETOP 2017, 2017, Hangzhou, China 


\title{
The Exploration and Practice of the Integrative and Continuous Optoelectronic Practical Teaching System
}

\author{
Wang Ying*a , Zhang Xinliang ${ }^{\mathrm{a}}$, Yang Xiaofei ${ }^{\mathrm{a}}$, Kuang Xiulin ${ }^{\mathrm{b}}$,

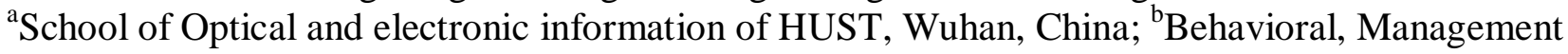 \\ and Social sciences of University of Twente, 7500AE Enschede, the Netherlands
}

\begin{abstract}
As a national pilot institute of the educational reform on practical teaching, an integrative and continuous practical teaching was established and implemented through four measures: promote a practical teaching system that is available for every undergraduate throughout their whole bachelor program; integrate the design of theoretical the practical teaching to closely associate the theoretical course with practical teaching; construct a complete practical teaching system by including experiment teaching, course design, project practice and extracurricular innovative practice; improve the level of practical teaching by appropriately allocating scientific research team, relevant personnel and resource. Based on the exploration and practice of this kind of practical teaching system, the integrative competence and quality of the undergraduates and graduates are both improved..
\end{abstract}

Keywords: practical teaching, integrative and continuous, available for every undergraduate

\section{INTRODUCTION}

Nowadays, the implementation of innovation-driven development is one of the main development strategies of China. The construction of an innovative country requires a large number of innovative talents in science and technology, thus the cultivation of talents in higher education should serve the strategic needs of the country. As a national pilot institute of a national 985 university, our faculty should also take the responsibility of cultivating talents that have good virtue, excellent academic skills, solid theoretical base and outstanding engineering capacity on optoelectronics science and technology.

Modern science and industry technology has no obvious boundaries, especially for the optoelectronics domain. The connection among optoelectronics research, development and products is almost seamless. As a high-tech industry, optoelectronics highly demands innovative and competent talents from higher education. Bachelor programs on optoelectronics are established in about 300 colleges and universities nationwide, including about 70-80 thousands students. Therefore, the exploration and practice on teaching strategies in pilot institutes for cultivating optoelectronic talents are of great practical significance.

Practical teaching is a key strategy in reaching the cultivating objectives of education, and is also an important way in improving students' integrative competence. It not only plays an important role in cultivating students' innovative spirit and engineering capacity, but also in improving graduates' social competitiveness and professional development. Although the content and system in previous practical teaching on optoelectronics can help students to strengthen, integrate and practice the knowledge learnt from class, and some top students can participate in innovative practice, gaps still exist in the availability, the comprehensiveness and extensibility of the practical teaching, which count much in the development of students' integrative competence and innovation capacity.

\section{PRACTICAL TEACHING PHILOSOPHY AND GOALS}

The educational philosophy and goals of the practical teaching in our faculty are promoted based on three considerations: first, the aforementioned problems on the limited availability, the monotonous content, and the weakness in

*wy@hust.edu.cn; phone +86 27 87543855-1; fax +86 27 87543855-6; english.oei.hust.edu.cn.

14th Conference on Education and Training in Optics and Photonics: ETOP 2017, edited by Xu Liu,

Xi-Cheng Zhang, Proc. of SPIE Vol. 10452, 104521G · ( 2017 ICO, IEEE, OSA, SPIE

CCC code: $0277-786 X / 17 / \$ 18 \cdot$ doi: $10.1117 / 12.2269370$

Proc. of SPIE Vol. 10452 104521G-1 
comprehensiveness and extensibility of practical teaching; second, the national educational objectives to cultivate bachelor students who are "theoretical-based, competent, research-based and international"; third, the demand of highquality professionals for optoelectronics domain and relevant industry development. In terms of all these three aspects, the practical teaching philosophy in our faculty was proposed as "available for every undergraduate, cultivate capability in practice, relate theories with practice to form an integrative practical teaching system, continuous innovative education".

Under the overall requirements of the cultivating plan, the objectives of the practical teaching system design are: improving subject-oriented capability by laying emphasis on knowledge acquisition and scientific methods; enhancing engineering and innovative ability by focusing on integrative capability and engineering quality. The methods to enrich students' practical experience mainly include experiments, course design, innovative practice and graduation project. Through these practical methods, the objectives can be reached from three steps: the first step is to help students to arouse students' learning interest, construct the concept of system, and enhance their sense of identity to the optoelectronics; the second step is to facilitate students' theory learning and corresponding hands-on ability; the third step is to improve design, research and engineering capacity, and to develop innovative awareness.

The implementation methods of the practical teaching in our faculty are: promoting a practical teaching system that is available for every undergraduate throughout their whole bachelor program; integrating the design of theoretical the practical teaching to closely associate the theoretical course with practical teaching; constructing a complete practical teaching system by including experiment teaching, course design, project practice and extracurricular innovative practice; improving the level of practical teaching by appropriately allocating scientific research team, relevant personnel and resource.

\section{CONSTRUCTING INTEGRATED PRACTICAL TEACHING SYSTEM}

Based on the national objectives to cultivating "theoretical-based, competent, research-based and international" undergraduates, the cultivating objectives of the bachelor program Optoelectronic Information Science and Engineering focus on the practice-based capability cultivation, of which curricular experiments, course design, and extracurricular projects are the main means of students' practice.

\subsection{The structure of the practical teaching system}

The practical teaching system for the bachelor program Optoelectronic Information Science and Engineering mainly consists of five levels (see Figure 1), namely: 1, professional cognitive practice; 2, basic experiments on optoelectronic; 3 , design practice on optoelectronic system (course design); 4, capacity promotion program (comprehensive research practice); 5, graduation project:

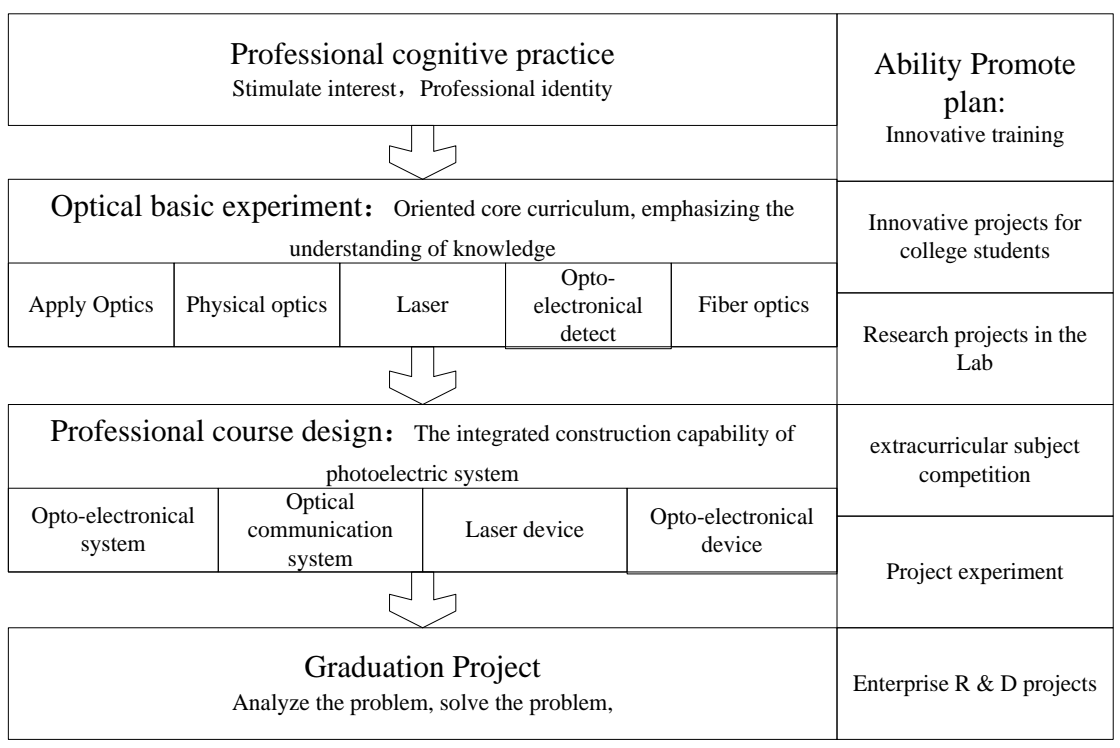

Figure 1. Practical teaching system architecture.. 
The first level professional cognitive practice aims to arouse students' learning interest, enhance their sense of identity to the optoelectronics, and help them to build the association among optoelectronic profession, systems and products. The second level basic experiments on optoelectronics have been inherited for decades, the contents of the experiments closely relates to the theoretical courses, which can enable students to understand the relation between theory and practice as well as to grasp basic experimental techniques, analytical methods and operational skills. The third level professional course design aims to strengthen students' analysis and design capabilities on professional optoelectronic system and to enhance their integration and application of knowledge. The fourth level capacity promotion program is a long-term program, within which every undergraduate should be involved in both curricular and extracurricular projects to strengthen their innovative capacity throughout three and a half academic years. The last level is the graduation project. Students are required to accomplish a project independently by following a process of concept promotion, design, implementation and evaluation, and to use research methods that are relevant to the optoelectronics domain. This graduation project is also a way to examine students' learning outcomes at the end of their bachelor program.

\subsection{Practical teaching and capacity cultivation $\mathrm{s}$}

The undergraduates in our faculty are expected to graduate with solid theoretical knowledge base on optoelectronics, with enough capacity on diagnosing engineering systems, and with high potential to take advantage of their knowledge and capacity in developing innovative designs and responding to the technological, social and economic development and changes [1]. To achieving these goals, the objectives to be accomplished by practical teaching are: students grasp basics skills on optoelectronics, understand the relationship between theoretical concepts and practical situation, and can use what they have learnt in solving practical problems. The practical teaching plan was designed by taking students' phased capacity requirements into consideration (see Figure 2). Different levels of practical tasks were set to cultivate their capacity and skills gradually.
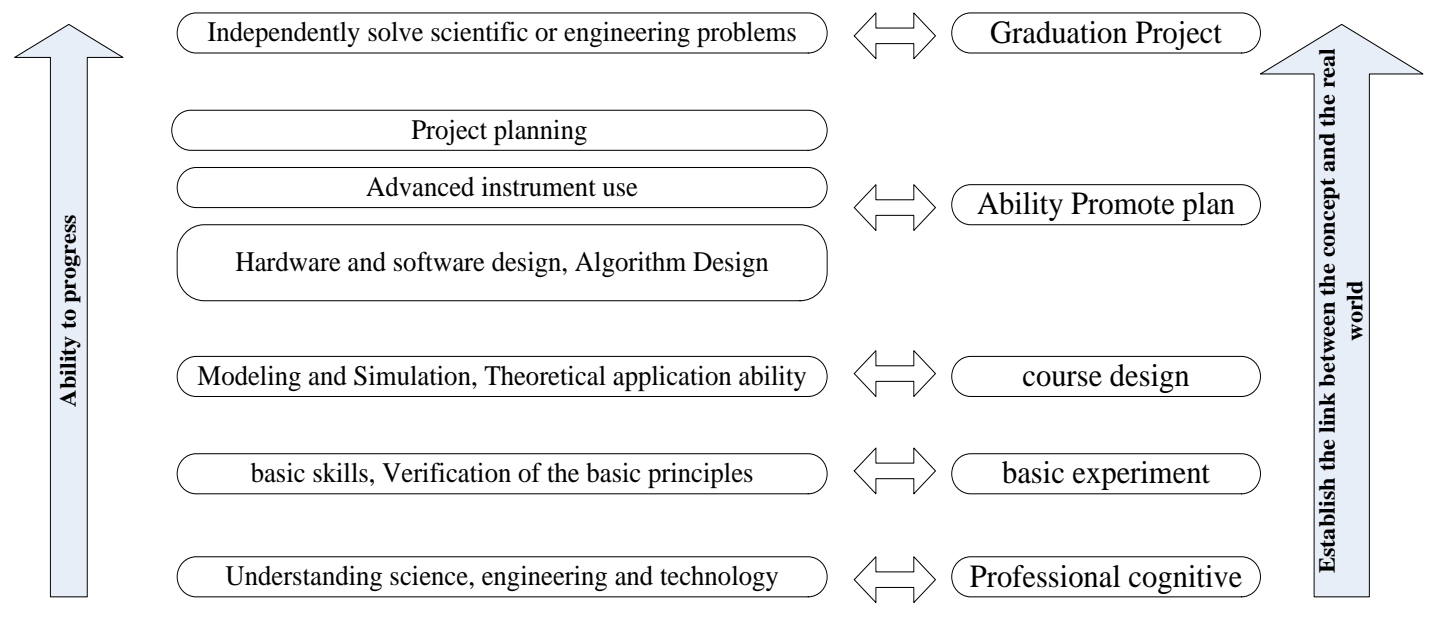

Figure 2. The relationship between the design of practical teaching and the capacity requirements

\section{THE EXPLORATION OF PRACTICAL TEACHING}

\subsection{Building the capacity promotion program aiming at cultivating the innovative capacity for every student}

Decades of practice on practical teaching and experience from both international and domestic indicated that extracurricular scientific research programs can benefit bachelor students with scientific awareness, team spirit, research ability and integrative competence. The extracurricular research programs are also of important significance in cultivating students' independent thinking and working competence [2]. However, the previous extracurricular research programs, or capacity promotion programs, are only available for excellent students, talent students or specially selected students. As a national pilot institute of the educational reform on practical teaching, every undergraduate that major in Optoelectronic Information Science and Engineering in our faculty can participate in this kind of extracurricular program.

Under the guidance of the principle "available for every undergraduate", the capacity promotion program in our faculty is both universal and flexible. More choices are provided for students to meet their individual needs and different levels 
of ability. Through the program, every student will experience the whole process of a scientific research through finishing a project, summarizing the outcome of the project and writing research papers about the project.

\begin{tabular}{|c|c|c|c|c|c|c|c|}
\hline Category & Management & \multicolumn{4}{|c|}{$\begin{array}{l}\text { Research activities instructor } \\
\text { as the first person in charge }\end{array}$} & \multicolumn{2}{|c|}{$\begin{array}{l}\text { Evaluation: } \\
\text { Portfolio } 50 \%+\text { paper } 50 \%\end{array}$} \\
\hline $\begin{array}{l}\text { Sci. Lab } \\
\text { Train }\end{array}$ & $\begin{array}{l}\text { Teaching } \\
\text { Laboratory }\end{array}$ & \multicolumn{2}{|c|}{$\begin{array}{c}\text { pilot class } \\
\text { students with academic } \\
\text { tutor }\end{array}$} & \multicolumn{2}{|c|}{$\begin{array}{l}\text { Independent research In the } \\
\text { Lab }\end{array}$} & $\begin{array}{l}\text { Teaching } \\
\text { Laboratory }\end{array}$ & \multirow{4}{*}{ instructor } \\
\hline $\begin{array}{l}\text { Spontaneous } \\
\text { project } \\
\text { Train }\end{array}$ & Project Lab & $\begin{array}{l}\text { Innovative projects } \\
\text { for college students }\end{array}$ & $\begin{array}{r}s \\
\text { com! }\end{array}$ & $\begin{array}{l}\text { abject } \\
\text { etition }\end{array}$ & $\begin{array}{l}\text { Enterprise R \& D } \\
\text { projects }\end{array}$ & Project Lab & \\
\hline \multirow[b]{2}{*}{$\begin{array}{l}\text { Organized } \\
\text { project } \\
\text { Train }\end{array}$} & \multirow[b]{2}{*}{$\begin{array}{l}\text { Teaching } \\
\text { Laboratory }\end{array}$} & \multicolumn{3}{|c|}{ Project practice (extracurricular) } & \multirow[b]{2}{*}{$\begin{array}{l}\text { Photoelectric } \\
\text { innovation } \\
\text { practice }\end{array}$} & \multirow[b]{2}{*}{$\begin{array}{l}\text { Teaching } \\
\text { Laboratory }\end{array}$} & \\
\hline & & \multicolumn{3}{|c|}{$\begin{array}{c}\text { Continuation project of Course Design } \\
\text { orminiproject } \\
\text { Progressive course } \\
\text { Project practice } \\
\end{array}$} & & & \\
\hline
\end{tabular}

Figure 3. The content of the capacity promotion program

The evaluation of students' performance on this capacity promotion program is from two aspects: the research process and the research outcome. The main research processes refer to a student's participation in the research project of his/her supervisor, in the innovative projects for undergraduates, in academic competitions and in extracurricular and curricular projects, etc. The research outcome denotes the academic papers.

As this capacity promotion program is characterized by its diversification and fragmentation, the difficulties of its implementation lie in the supervision and evaluation of the process and quality. To account for this, the portfolio assessment is introduced as a management tool to manage and control the whole process [3].

This capacity promotion program can not only help to improve students' integrative competence but also can help students to gradually form the rigorous style and the moral character on academic research.

\subsection{Construction of multiple and progressive teaching projects}

\subsubsection{Progressive courses based on projects}

Starting from the professional cognitive practice, a series of progressive courses were established based on projects. Taking the three-dimensional digital manufacturing project as an example, 6 practical courses relevant to this project were set throughout the four academic years (see Table 1).

Table 1 . The content of the progressive courses on 3D digital manufacturing project.

\begin{tabular}{|l|l|l|}
\hline No. & \multicolumn{1}{|c|}{ Course name } & \multicolumn{1}{c|}{ Content } \\
\hline 1 & $\begin{array}{l}\text { Cognition: 3D Digital } \\
\text { Manufacturing }\end{array}$ & $\begin{array}{l}\text { Build 3D model and output as STL format; Study the process } \\
\text { parameters and perform 3D printing; }\end{array}$ \\
\hline 2 & Technology: DIY 3D Printer & $\begin{array}{l}\text { Machinery, circuit and software installation; printer adjustment; printer } \\
\text { calibration and spec definition. }\end{array}$ \\
\hline 3 & Analysis of 3D Modeling & TOF; stereo; structured light; building point cloud \\
\hline 4 & $\begin{array}{l}\text { Control: Arduino as 3D printer } \\
\text { Firmware }\end{array}$ & $\begin{array}{l}\text { Arduino hardware introduction; Arduino IDE and basic programming; } \\
\text { PID motion control; 3D printing work beat; 3D printing control } \\
\text { program; open source and its impact on the society (seminar) }\end{array}$ \\
\hline 5 & $\begin{array}{l}\text { Foftware: 3D printing algorithm and } \\
\text { software }\end{array}$ & $\begin{array}{l}\text { Introduction of 3D printing software Repetier-Host; STL file structure; } \\
\text { slicing; path planning; G code generation }\end{array}$ \\
\hline UV laser curing & $\begin{array}{l}\text { 3D printer spec analysis; The way of improving precision and } \\
\text { resolution; Laser beam characteristics; modulation and control; laser } \\
\text { control using on the Arduino Mega 2560; Modified the 3D printer into } \\
\text { 3D rapid prototyping with UV laser. }\end{array}$ \\
\hline
\end{tabular}




\subsubsection{Progressive courses based on projects}

The project-based practical teaching program is implemented continuously and progressively to the undergraduates. Take the teaching program on monocular as an example, as shown in Figure 4, in the first academic year, students can learn how to use a monocular and how to evaluate the using effects from the professional cognitive practice. In the second academic year, students will participate in some experiments on applied optics, within which they have to measure the optical parameters of the monocular. During the experimental process, their understanding about the optical parameters can be improved. Apart from the optical experiments, they are also required to finish a course design project on designing a monocular with Zmax optical software in this year. In the third academic year, students will be involved in the optical-physics experiments on the transfer function, and learn the transfer function of wave aberration. They have to evaluate the quality of a monocular by using this function. In the last academic year, students will participate in the modern optical experiment. Monocular is used in Phase-shifting interferometry as laser beam extender in the experiment, and students are asked to evaluate their effect on the measurement results.

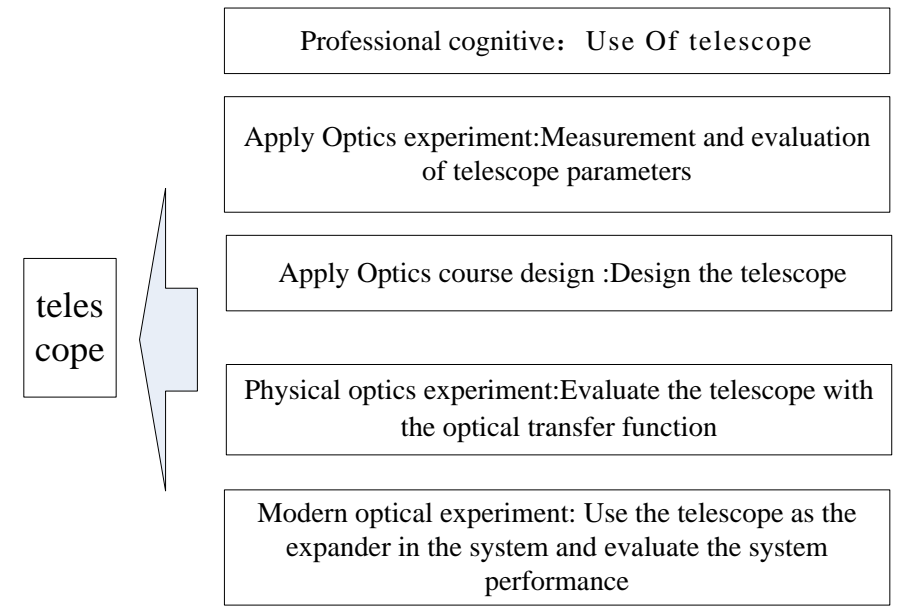

Figure 4. The content of the monocular program.

\subsubsection{Progressive topic experiments based on experimental platform}

The practical teaching program aims to build series of progressive experiments that center on every single key topic of the optoelectronics domain on a set of experimental platform. It also enables the sharing among various grades and courses. A four-year continuous learning on these kinds of well-designed topic experiments can benefit students with deeper and more effective learning on abstract concepts.

As an example to clarify the progressive experiments on a single topic, the topic interference and the relevant experiments with the Mach-Zehnder interferometer module is explained as follows:

L 1

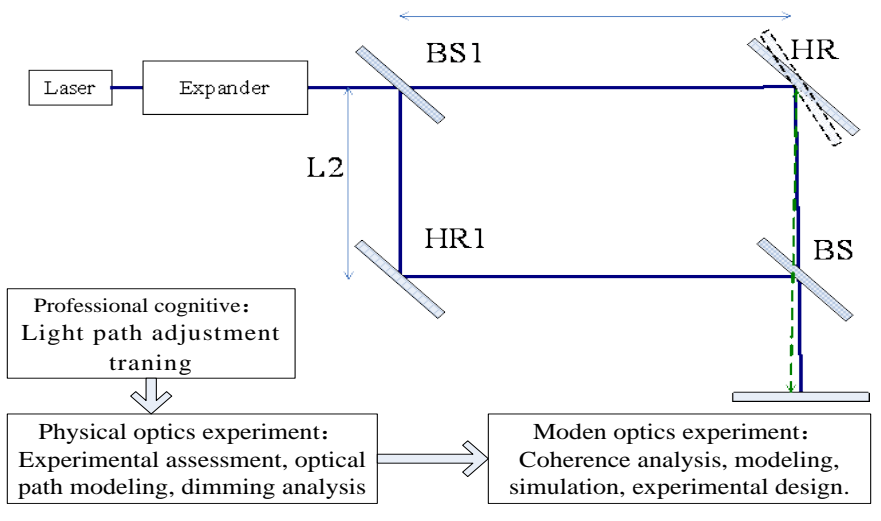

Figure 5. The progressive experiments concerning the Mach-Zehnder interferometer. 
The freshmen can practice their basic skills on dimming through the cognitive practice. The senior students are required to pass an assessment on optical-physics experiments. During the assessment, their performance on analyzing the interference optical path and hands-on operations will be evaluated. The students in their final academic year will follow the modern optical experiments. Within the experiments, they have to do design, modeling, simulation, experiments and outcome evaluation about the coherence between the time and space of the light source.

\subsection{Construct professional, integrative practice in course design}

After students are equipped with enough professional knowledge and basic skills, they can practice what they have learnt in some course design projects, such as optical fiber communication system course design, photoelectric system course design, optoelectronic device course design and laser device course design.

Taking the photoelectric system course design as an example, the practical devices included in this project are: photoelectric pulse tester, traffic light controller, optoelectronic intelligent tracking car, photoelectric elevator controller etc. Students need to conduct both theoretical and simulated analysis, and to decompose and analyze the technical index needs under the guidance of the teacher. Students are also asked to comprehensively use the optical, the machine, the electricity and cultivation in finishing the course design.

\subsection{Converting the disciplinary development into high-quality teaching resource for undergraduates in time}

\subsubsection{A scientific research practice course -- "photoelectric innovation practice"}

"Photoelectric innovation practice" course is an outcome of the exploration on opening the disciplinary resource to the cultivation of undergraduates. This practical course is established based on the abundant research strength of four national research bases: Wuhan National Laboratory for Optoelectronics, the State Key Laboratory of Laser Technology, the National Engineering Research Center of Laser Processing, and the National Engineering Laboratory of the Next Generation Access Network. This course is an optional course, and all the projects included in this course are solicited from the scientific research teams of the entire faculty. The course contents are some operational parts from the scientific research projects, such as the analysis of the dynamic process, the establishment of structural model, experimental research, and algorithm design, etc. Besides, students' monographic study will be implemented within the research group. This course has been established for 8 years, hundreds of students have experienced the scientific research process and have been influenced by the scientific spirit.

\subsubsection{The core course group strongly supports the experimental teaching}

The responsible professor of an experimental course is the group leader or the core lecturer appointed by the core course group. This professor takes the responsibility of the planning, development, audit for upgrade, and outline formulation of the experimental course, thus solving the sustainability issues of the experimental course. The lab instructor will participate in the core course group, and the core course group will also send out a core lecturer as the experimental guider. Through this way, the quality of the experimental guidance has been improved. Experimental teaching supported by high-quality research resource and guiders can benefit students.

\section{SUMMARY}

We built a four-year innovative framework for practical teaching. This practical teaching system has advantage in integrating theory, practice and research activity. A series of teaching measures have been taken in this practical teaching system, including setting up the capacity promotion program that aiming to cultivate the innovative capacity of every student, establishing multiple and progressive practical projects, constructing integrative course designs, and converting the disciplinary development into high-quality teaching resource. Through these ways, the concepts, contents and teachers of the practical teaching for optoelectronic have been extended. In addition, more diverse participating ways and personalized development plans are provided for students in the practical teaching system, which has motivated students' enthusiasm in active learning and has significantly improved their integrative competence.

\section{REFERENCE LINKING}

[1] Li Manli, "The Unique Cultivation of Exemplary Engineering Innovator, " UNIVERSITY EDUCATION SCIENCE 120(2), 91-96(2010). 
[2] Ye Ming, Wei Zhiyuan, Lou Chengfu, Mao Yipin . "S RT: Successful Exploration of Undergraduate Teaching Reform in Zhejiang University," Research on Higher Engineering Education (4), 55-58(2005).

[3] S Shay, "Portfolio assessment: A catalyst for staff and curricular reform, " Assessing Writing 4(1), 29-51(1997).

[4] Liu Zhaoqing, [The study of the evaluate reform based on the excellent engineer training], Master's Degree Thesis of Huazhong University of Science and Technology, 31-42(2013). 